\title{
Influence of alkali ions on the efficiency of shrinkage reduction by polypropylene glycol in alkali activated systems
}

\author{
Lukas Kalina \\ Senior researcher, Faculty of Chemistry, Materials Research Centre, Brno, \\ Czech Republic (corresponding author: kalina@fch.vut.cz) \\ (Orcid:0000-0001-8127-8175) \\ Vlastimil Bilek Jr \\ Junior researcher, Faculty of Chemistry, Materials Research Centre, Brno, \\ Czech Republic (Orcid:0000-0003-3831-3443)
}

\begin{abstract}
Alkali-activated materials, especially when activated by water glass, exhibit substantial drying shrinkage that hinders their broader industrial application. The effect of shrinkage-reducing admixtures (SRA), based on polypropylene glycol, on drying shrinkage of alkali-activated blast furnace slag (BFS) mortars was examined. The determination of SRA efficiency and the influence of potassium alkali activators with varying silicate modulus on drying shrinkage characteristics were studied. It was observed that a high amount of alkalis positively affected the effect of SRA. The higher the amount of alkalis was, the lower was the drying shrinkage. The paper further discusses and underlines the role of the amount of alkali ions on the properties of alkali-activated BFS systems.
\end{abstract}

\section{Introduction}

High energy consumption and increased emissions along with ageing infrastructure have a harmful impact on the environment. Every year the production of concrete exceeds $10^{10} \mathrm{t}$, which is more than all other man-made materials combined. Such a huge production results in approximately $5 \%$ of the world's total anthropogenic greenhouse gas emissions (Damtoft et al., 2008). Nowadays, this fact brings an even greater need to develop more environmentally friendly materials, which are more durable, highly recyclable and energy efficient.

Alkali-activated materials (AAMs) have become the materials of interest mainly owing to their low environmental impact compared to Portland cement and also because of the possibility of using varieties of industrial waste (Kalina et al., 2012). The utilisation of AAM as an alternative binder instead of ordinary Portland cement (OPC) adds sustainability to concrete by reducing the carbon dioxide $\left(\mathrm{CO}_{2}\right)$ emissions compared to cement production. Many scientific studies have revealed that some kinds of AAM are distinguished by superior durability and lower heat of hydration compared to OPC binder, high resistance to aggressive environments (Hossain et al., 2015) and good performance in high temperatures (Bernal et al., 2015). Another advantage could be better behaviour under freeze-thaw cycles (Cai et al., 2013). However, these materials exhibit drying and autogenous shrinkage (Bilek et al., 2016), the subsequent formation of microcracks and higher formation of salt efflorescence, which are the major drawbacks that hinder these materials' broader industrial application.

Only a few authors have studied possible ways of reducing the shrinkage, which could be carried out using shrinkagereducing admixtures (SRAs), belonging to the group of surfactants. The effect of SRA has been well investigated in Portland cement systems (Sant et al., 2010); however, only little attention was dedicated to the study of efficiency of SRAs in alkali-activated slag (AAS) systems. It was concluded that the decrease in the surface tension of pore solution caused by SRA brought about smaller internal stress when the water evaporated. This resulted in the capillary stress being much lower than without the admixture. In terms of the drying shrinkage, the content of mesopores also plays a crucial role. According the capillary pressure theory (Bentz et al., 1995), the system with a higher content of mesopores exhibits higher drying shrinkage (Collins and Sanjayan, 2000). The presence of SRA causes pore size redistribution (Palacios and Puertas, 2007), meaning that SRA decreases the percentage of mesopores in the total porosity of AAMs.

The SRA efficiency is entirely influenced by the nature of the electrolyte solution in which the SRA is located (Bauduin et al., 2004; Morini et al., 2005). There are two effects that have to be taken into account. The 'salting-in' effect initiates the solubilisation or miscibility of the surfactant in an aqueous electrolyte solution. By contrast, the 'salting-out' effect causes a decrease of the critical micelle concentration (CMC), increases the liquidliquid miscibility gap and enhances the self-organisation. The question is whether the salting-in or the salting-out effect dominates in AAM. A high content of alkali ions in the system would imply that, for the AAM, salting-in may occur. However, the amount and the kind of cations in the pore solution significantly impact the surfactant's behaviour, as the Hofmeister or the lyotropic series suggest (Kunz et al., 2004). To sum up, the present investigation is therefore focused on the role of specific alkali activators with different amounts of alkali ions influencing the shrinkage evolution and other properties of alkali-activated 
blast furnace slag (BFS) systems with and without specific SRA based on polypropylene glycol.

\section{Experiment}

\section{Materials}

The aluminosilicate material used for the alkali activation was BFS from ArcelorMittal Ostrava, Inc., Czech Republic, with a specific surface area of $400 \mathrm{~m}^{2} / \mathrm{kg}$. The chemical composition specified by X-ray fluorescence spectroscopy (XRF) is shown in Table 1. The crystalline composition of BFS determined by $\mathrm{X}$-ray diffraction (XRD) confirmed the presence of merwinite, melilite, $\beta-\mathrm{C}_{2} \mathrm{~S}$ and calcite. The BFS was activated by potassium water glass (Vodni sklo, Inc.) with defined silicate moduli: $M_{\mathrm{s}}=1.92(4 \%) ; 1.29(6 \%) ; 0.97(8 \%) ; 0.78(10 \%)$. The silicate moduli (silicon dioxide to potassium oxide $\left(\mathrm{SiO}_{2} / \mathrm{K}_{2} \mathrm{O}\right)$ molar ratio) correspond to the weight of potassium oxide in the activator, recalculated to the amount of BFS, as is shown in brackets. Three different fractions of standard siliceous sand (ॅ̌SN EN 196-1) were used for mortar preparation. The surfactant serving as the SRA was polypropylene glycol (PPG 425) with a specific molar weight, $M_{\mathrm{w}}=425$ (Sigma Aldrich, Ltd.). The amount of PPG 425 added into the alkali-activated mixture was determined as $0.5 \mathrm{wt} \%$, recalculated to the amount of BFS.

\section{Methods}

\section{Pore solution characterisation}

The pore solutions were extracted from samples activated by water glass with different silicate moduli after $24 \mathrm{~h}$ using the hydraulic press BS-3000 (manufactured by BetonSystem company). After $24 \mathrm{~h}$, the chemical composition of the pore solution did not change substantially and this time also indicates the beginning of drying shrinkage measurement. One hundred microlitres of pore solution were placed into a $100 \mathrm{ml}$ volumetric flask and filled with water. The samples were then analysed by inductively coupled plasma optical emission spectrometry Horiba Ultima 2 (Horiba Scientific). The concentrations obtained were then used for synthetic preparation of pore solutions, which were further used for the surface tension measurement.

\section{Surface tension testing}

The surface tension of prepared samples was measured by the tensiometer BPA-800P (KSV Instruments) using the maximum bubble pressure method. The measurement was carried out in standard mode under the laboratory temperature $\left(21^{\circ} \mathrm{C}\right)$. The pore solution was weighed out into plastic flasks, one containing the reference sample and the others containing PPG 425 in the mass concentrations of $0 \cdot 05,0 \cdot 10,0 \cdot 25,0 \cdot 50$, 1.00 and $2.00 \mathrm{wt} \%$ related to the mass of BFS, the amount of which corresponded to the amount of activator used that was necessary for alkali activation.

\section{Drying shrinkage measurement}

The mortar specimens were prepared according to $\check{C} S N$ EN 196-1 (ČSN, 2016) standard with the dimensions of $25 \times 25 \times 285 \mathrm{~mm}$ and were subjected to the drying shrinkage tests according to ASTM C596 (ASTM, 2017b). After $24 \mathrm{~h}$ the specimens were removed from molds and kept in the $n$ humidity chamber at approximately $50 \% \mathrm{RH}$ until the age of $28 \mathrm{~d}$. During this period, the relative length changes were measured almost every workday at the beginning and then usually every $3 \mathrm{~d}$ using the ASTM C490 (ASTM, 2017a) dilatometer.

\section{Isothermal calorimetry measurement}

All calorimetric measurements were performed using TAMAir isothermal conduction calorimeter by TA Instruments at the temperature of $25^{\circ} \mathrm{C}$. For each measurement, $4 \mathrm{~g}$ of BFS and adequate amount of alkali activator were used. Slag was placed into $15 \mathrm{ml}$ glass flask and alkali activator was dosed into admix vial. BFS and the activator were inserted into the calorimeter and tempered separately (for approximately $3 \mathrm{~h}$ ), then mixed together and stirred for 2 min with a teflon stirrer. A siliceous sand was used as a reference sample. The amount of reference was chosen so that it had similar heat capacity as the sample, in this case being $15.5 \mathrm{~g}$ of reference.

\section{Compressive strength testing}

For the compressive strength measurement, the testing mortar samples with the diameters of $40 \times 40 \times 160 \mathrm{~mm}$ were prepared according to ČSN EN 196-1 standard. Each value in compressive strength development was supported by the average of four measurements. The tests were performed at the ages of $24 \mathrm{~h}, 7 \mathrm{~d}$ and $28 \mathrm{~d}$ after the specimen preparation. The press BS-300 (BetonSystem) was used for the compressive strength measurement.

\section{Results and discussion}

First, the most suitable PPG 425 concentration for the test of drying shrinkage was determined. The dependence of surface tension of pore solutions on PPG 425 concentration is represented in Figure 1. Each pore solution extracted from samples activated by water glass of specific silicate moduli contained a

Table 1. Chemical composition of BFS according to XRF

\begin{tabular}{|c|c|c|c|c|c|c|c|c|c|c|}
\hline \multirow[b]{2}{*}{ Raw material } & \multicolumn{10}{|c|}{ Chemical composition: wt \% } \\
\hline & $\begin{array}{c}\text { Silicon } \\
\text { dioxide } \\
\left(\mathrm{SiO}_{2}\right)\end{array}$ & $\begin{array}{c}\text { Aluminium } \\
\text { oxide } \\
\left(\mathrm{Al}_{2} \mathrm{O}_{3}\right)\end{array}$ & $\begin{array}{l}\text { Calcium } \\
\text { oxide } \\
(\mathrm{CaO})\end{array}$ & $\begin{array}{l}\text { Sodium } \\
\text { oxide } \\
\left(\mathrm{Na}_{2} \mathrm{O}\right)\end{array}$ & $\begin{array}{c}\text { Potassium } \\
\text { oxide } \\
\left(\mathrm{K}_{2} \mathrm{O}\right)\end{array}$ & $\begin{array}{c}\text { Magnesium } \\
\text { oxide } \\
(\mathrm{MgO})\end{array}$ & $\begin{array}{l}\text { Sulfur } \\
\text { trioxide } \\
\left(\mathrm{SO}_{3}\right)\end{array}$ & $\begin{array}{l}\text { Iron (III) } \\
\text { oxide } \\
\left(\mathrm{Fe}_{2} \mathrm{O}_{3}\right)\end{array}$ & $\begin{array}{c}\text { Titanium } \\
\text { dioxide } \\
\left(\mathrm{TiO}_{2}\right)\end{array}$ & $\begin{array}{c}\text { Manganese } \\
\text { oxide } \\
\text { (MnO) }\end{array}$ \\
\hline BFS & $34 \cdot 7$ & $9 \cdot 1$ & $41 \cdot 1$ & $0 \cdot 4$ & 0.9 & $10 \cdot 5$ & $1 \cdot 4$ & 0.3 & $1 \cdot 0$ & 0.6 \\
\hline
\end{tabular}


different amount of potassium ions. Even a small addition of surfactant led to a steep drop of surface tension. This effect was also supported by the presence of alkalis. Generally, the more alkalis that were present in the solution, the lower was the surface tension, and thus they positively influenced the effect of admixture. This is in a good agreement with the Hofmeister series and salting-in effect. This dependence was observed for all pore solutions. Nevertheless, the surface tension values of pore solutions with $M_{\mathrm{s}}=0.78$ and 0.97 were basically the same within the deviation values. It can also be concluded that after a sudden decrease of surface tension the values did not change further but, on the contrary, they remained more or less constant for almost all solutions. This phenomenon occurred at the moment when the concentration of PPG 425 was $0.5 \mathrm{wt} \%$, meaning that the surfactant reached its critical micelle concentration (CMC) $\left(45-55 \mathrm{~mJ} / \mathrm{m}^{2}\right)$. As a consequence, it was concluded that $0.5 \mathrm{wt}$ $\%$ of PPG 425 should have been further added to the samples for the following measurements.

The efficiency of PPG 425 on the drying shrinkage development of potassium alkali-activated mortars is shown in Figure 2. The dependence of the drying shrinkage decrease on decreasing silicate modulus of the alkali activator is evident. This phenomenon is probably related to the formation of different amounts of calcium silicate hydrate $(\mathrm{C}-\mathrm{S}-\mathrm{H})$ gel. A higher amount of $\mathrm{C}-\mathrm{S}-\mathrm{H}$ gel causes a more compact structure, which leads to lower evaporation of water from the capillary menisci (Figure 3) and, therefore, the drying shrinkage is consequently smaller. Nevertheless, within the same silicate modulus of alkali activator, higher weight losses of mortars with PPG 425 were observed, compared to those without it. This could be explained by the lower liquid saturation induced by SRA as previously described (Aitcin and Flatt, 2015). Moreover, the amount of alkalis has a significant influence on drying shrinkage. Comparing the samples with

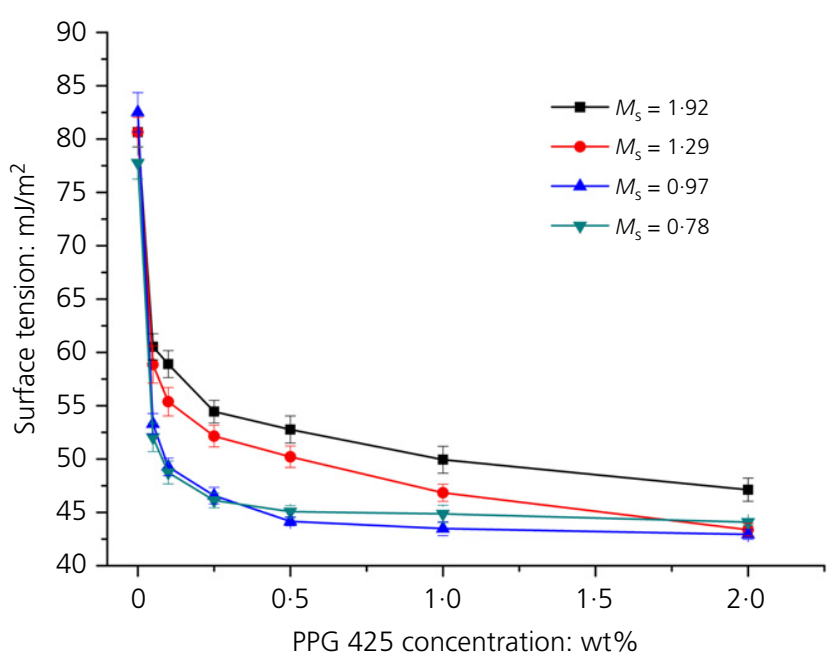

Figure 1. Surface tension of pore solutions with different silicate moduli of potassium water glass depending on the PPG 425 concentration
PPG 425 and the reference samples, the effect of added surfactant is evident. Thanks to the higher content of alkaline ions, the efficiency of PPG 425 increases. It is obvious that the samples activated by water glass with low silicate modulus $(0 \cdot 78 ; 0.97)$ show a greater difference between the reference and the surfactant-containing samples in drying shrinkage evolution. This phenomenon is in a good agreement with previous results presented in Figure 1 and confirms the importance of the amount of alkali ions for the PPG 425 efficiency affecting the reduction of surface tension of the pore solution and the drying shrinkage.

The hydration mechanism was studied based on the calorimetry measurement. Figure 4 presents slag pastes activated by

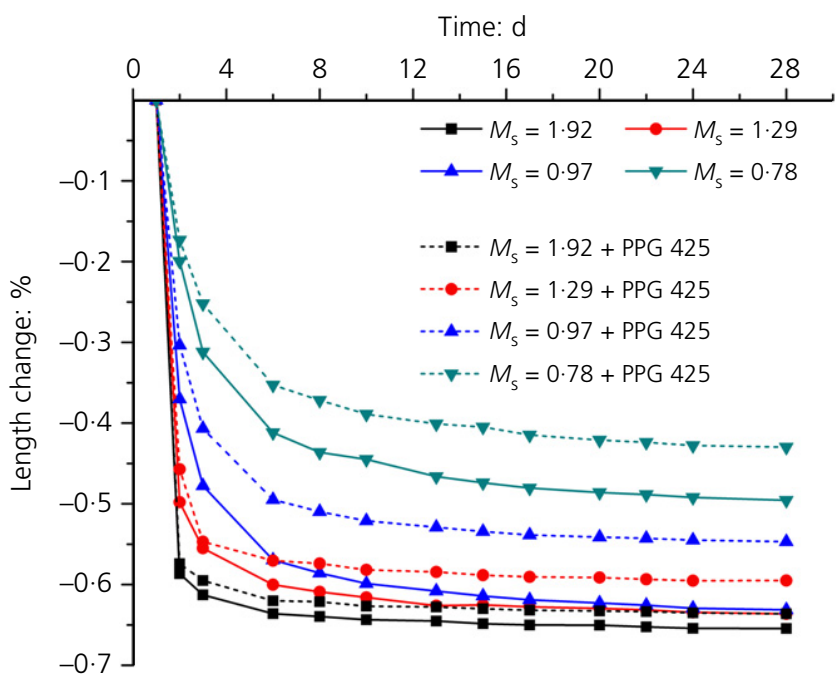

Figure 2. Effect of PPG 425 on drying shrinkage evolution of samples activated by potassium water glass with different silicate moduli

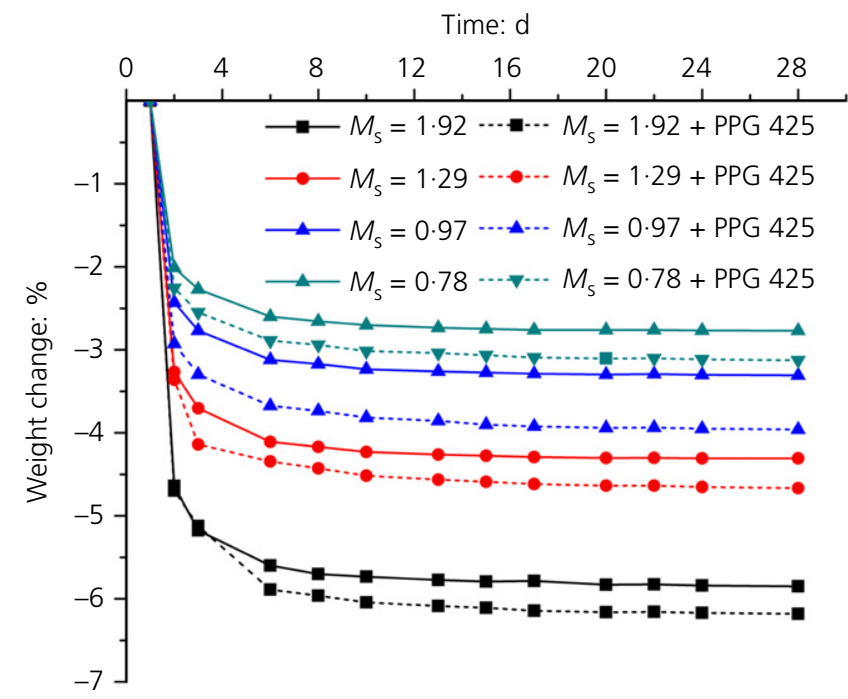

Figure 3. Effect of PPG 425 on weight changes of samples activated by potassium water glass with different silicate moduli 


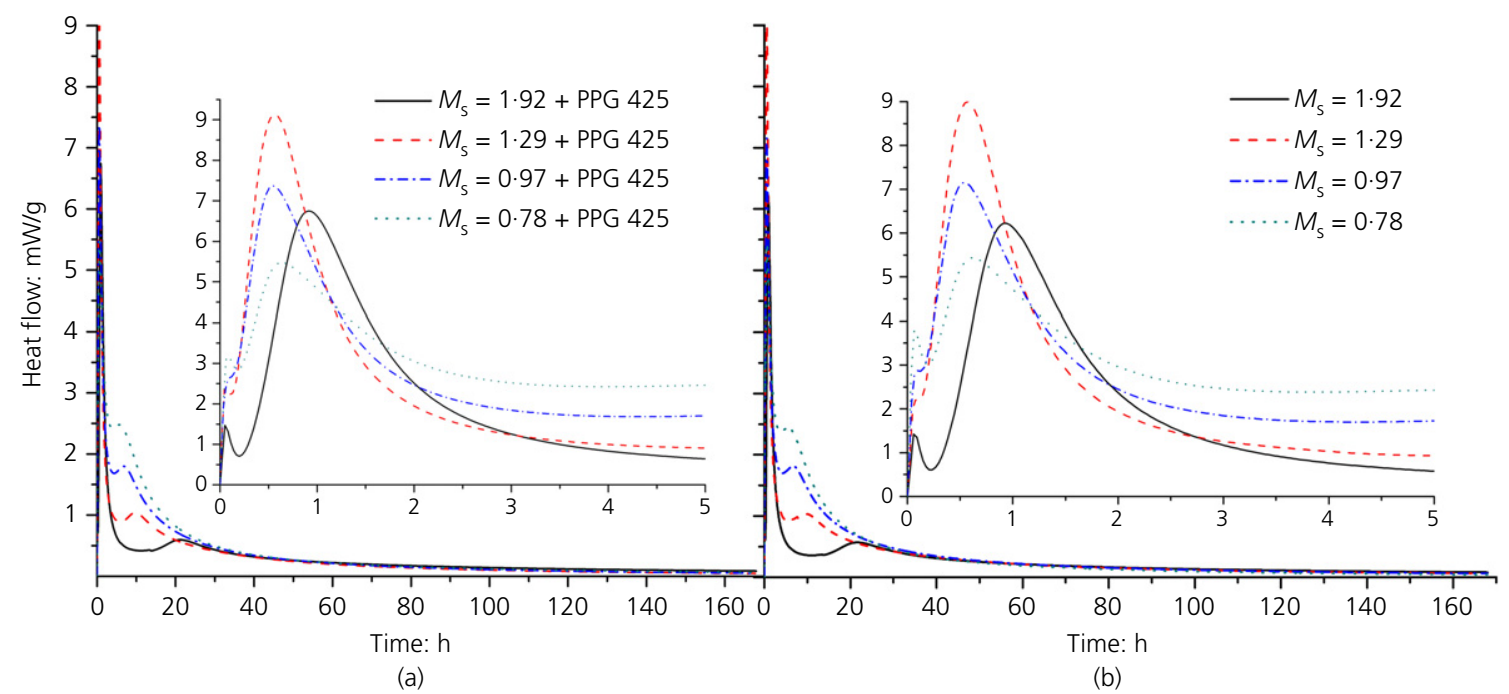

Figure 4. Heat evolution rate of slag pastes activated by potassium water glass with different silicate moduli: (a) with the addition of PPG 425 and (b) without it

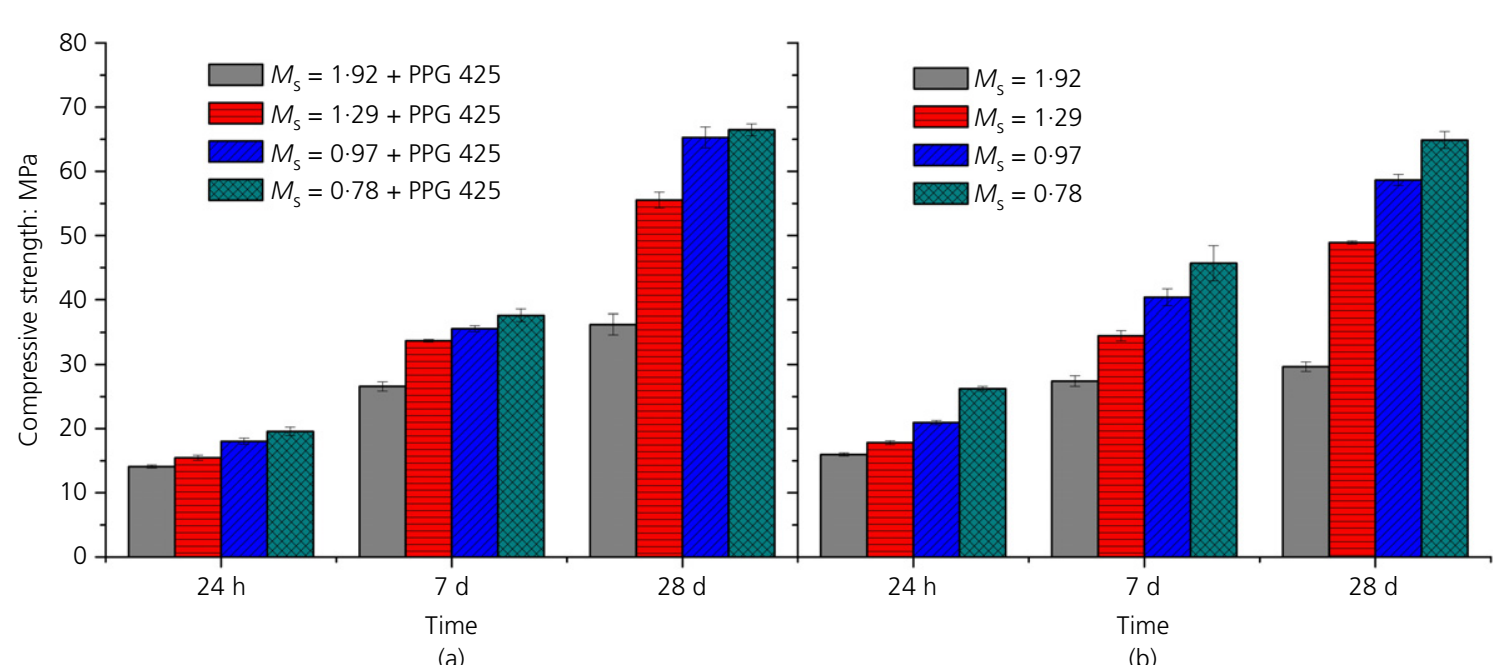

Figure 5. Effect of PPG 425 on the compressive strength development of samples activated by potassium water glass with different silicate moduli: (a) with the addition of PPG 425 and (b) without it

potassium water glass with varying silicate moduli $\left(M_{\mathrm{s}}=1.92\right.$, $1 \cdot 29,0 \cdot 97,0 \cdot 78)$. Figure 4(a) shows the heat flow evolution for the mixtures with added PPG 425, whereas Figure 4(b) demonstrates the curves for the mixtures without it. The amount of PPG 425 was always $0.5 \mathrm{wt} \%$ of BFS. Particular peaks capture various stages of the slag activation process. The first initial peak is always associated with particle wetting and slag dissolution and the second additional peak corresponds to primary C-S-H gel formation, both during the so-called pre-induction period (Shi and Day, 1995). Then the process is followed by the precipitation of the secondary $\mathrm{C}-\mathrm{S}-\mathrm{H}$ gel, and therefore the third peak was recorded. It was observed that the heat flow evolution remained the same for the mixtures with PPG 425 as well as without it. However, it was found that the samples activated by potassium water glass with various silicate moduli differed significantly in the third peak. Higher silicate modulus caused the delay of secondary $\mathrm{C}-\mathrm{S}-\mathrm{H}$ gel formation, and moreover decreased its heat flow release, which influenced the compressive strength development. When the mortars activated by potassium water glass were prepared, it was confirmed that the compressive strength was higher with decreasing value of silicate modulus of alkali activator (Figure 5). This trend is evident both in the samples with the addition of PPG 425 (Figure 5(a)) and in the reference samples (Figure 5(b)). The results are consistent with the calorimetry measurement, where it was proved that the samples activated by water glass with higher silicate modulus showed less formation of binder phase. It is also obvious that the addition of surfactant influences the compressive strength 
development. In the early stages of the alkali activation process (1-7 d), the compressive strength of samples with PPG 425 is lower compared to the reference samples. After $1 \mathrm{~d}$, the compressive strength of samples with PPG 425 achieved only $87 \%$ of the reference samples' values in cases of $M_{\mathrm{s}}=1.92,1.29,0.97$ and just $75 \%$ for samples activated by potassium water glass with silicate modulus $M_{\mathrm{s}}=0 \cdot 78$. This decrease could be related to possible adsorption of surfactant to the BFS particles, which slows down the process of alkali activation, as previously described (Partyka et al., 1984). After 7 d, the equalisation of compressive strengths of samples with surfactant and without it occurred, with respect to the error bars. However, the role of surfactant in preventing the drying shrinkage is visible after $28 \mathrm{~d}$. The samples with PPG 425 did not show any visible cracks on their surface, which positively affected the compressive strengths results; see, for example, the samples activated by water glass with $M_{\mathrm{s}}=0 \cdot 78$. While the compressive strength of the reference sample between 7 and $28 \mathrm{~d}$ has been augmented by $30 \%$, the strength of samples with PPG 425 added has improved by more than $40 \%$. A similar trend was also observed in other cases.

\section{Conclusions}

On the basis of the results obtained, it can be stated that polypropylene glycol with the molecular weight 425 plays a critical role in drying shrinkage development. Its efficiency is highly enhanced by the amount of alkalis in the activator. The addition of the surfactant used slightly decreases the compressive strength in the early stages of the hydration process (1-7 d), but after $28 \mathrm{~d}$ it gives better results compared to samples without it. These pieces of knowledge point out the importance of using suitable SRAs to improve the properties of AAMs and consequently increase the potential for their broader industrial application.

\section{Acknowledgements}

This outcome has been achieved with financial support by the project: Materials Research Centre at Faculty of Chemistry, Brno University of Technology - Sustainability and Development, REG LO1211, with financial support from the National Programme for Sustainability I (Ministry of Education, Youth and Sports) and GA17-03670S 'Development of shrinkage reducing agents designed for alkali activated systems', and with the financial support from the Czech science foundation.

\section{REFERENCES}

Aïtcin PC and Flatt RJ (2015) Science and Technology of Concrete Admixtures. Woodhead Publishing, Sawston, UK.

ASTM (2017a) C490/C490M-17: Standard practice for use of apparatus for the determination of length change of hardened cement paste, mortar, and concrete. ASTM International, West Conshohocken, PA, USA.

ASTM (2017b) C596-09: Standard test method for drying shrinkage of mortar containing hydraulic cement. ASTM International, West Conshohocken, PA, USA.

Bauduin P, Wattebled L, Touraud D and Kunz W (2004) Hofmeister ion effects on the phase diagrams of water-propylene glycol propyl ethers. International Journal of Research in Physical Chemistry \& Chemical Physics 218(6): 631-641.
Bentz DP, Quenard DA, Baroghelbouny V, Garboczi EJ and Jennings HM (1995) Modeling drying shrinkage of cement paste and mortar.1. Structural models from nanometers to millimeters. Materials and Structures 28(182): 450-458.

Bernal SA, Rodriguez ED, de Gutierrez RM and Provis JL (2015) Performance at high temperature of alkali-activated slag pastes produced with silica fume and rice husk ash based activators. Materiales de Construccion 65(318): 1-10.

Bilek V, Kalina L, Novotny R, Tkacz J and Parizek L (2016) Some issues of shrinkage-reducing admixtures application in alkali-activated slag systems. Materials 9(6): 1-12.

Cai LC, Wang HF and Fu YW (2013) Freeze-thaw resistance of alkali-slag concrete based on response surface methodology. Construction and Building Materials 49: 70-76, https://doi.org/10.1016/ j.conbuildmat.2013.07.045.

Collins F and Sanjayan JG (2000) Effect of pore size distribution on drying shrinkage of alkali-activated slag concrete. Cement and Concrete Research 30(9): 1401-1406.

ČSN (Czech Technical Standard) (2016) EN 196-1: Methods of testing cement - Part 1: Determination of strength. Czech Office for Standards, Metrology and Testing, Prague, Czech Republic.

Damtoft JS, Lukasik J, Herfort D, Sorrentino D and Gartner EM (2008) Sustainable development and climate change initiatives. Cement and Concrete Research 38(2): 115-127.

Hossain MM, Karim MR, Hossain MK, Islam MN and Zain MFM (2015) Durability of mortar and concrete containing alkali-activated binder with pozzolans: a review. Construction and Building Materials 93: 95-109, https://doi.org/10.1016/j.conbuildmat. 2015.05.094

Kalina L, Koplik J, Soukal F, Masilko J and Jaskowiecova L (2012) Potential uses of geopolymers to immobilize toxic metals from by-products materials. Environmental Engineering and Management Journal 11(3): 579-584.

Kunz W, Henle J and Ninham BW (2004) 'Zur Lehre von der Wirkung der Salze' (about the science of the effect of salts): Franz Hofmeister's historical papers. Current Opinion in Colloid \& Interface Science 9(1-2): 19-37.

Morini MA, Messina PV and Schulz PC (2005) The interaction of electrolytes with non-ionic surfactant micelles. Colloid and Polymer Science 283(11): 1206-1218.

Palacios M and Puertas F (2007) Effect of shrinkage-reducing admixtures on the properties of alkali-activated slag mortars and pastes. Cement and Concrete Research 37(5): 691-702.

Partyka S, Zaini S, Lindheimer M and Brun B (1984) The adsorption of non-ionic surfactants on a silica-gel. Colloids and Surfaces 12(3-4): 255-270.

Sant G, Eberhardt A, Bentz D and Weiss J (2010) Influence of shrinkage-reducing admixtures on moisture absorption in cementitious materials at early ages. Journal of Materials in Civil Engineering 22(3): 277-286.

Shi CJ and Day RL (1995) A calorimetric study of early hydration of alkali-slag cements. Cement and Concrete Research 25(6): 1333-1346.

\section{How can you contribute?}

To discuss this paper, please submit up to 500 words to the editor at journals@ice.org.uk. Your contribution will be forwarded to the author(s) for a reply and, if considered appropriate by the editorial board, it will be published as a discussion in a future issue of the journal. 